\title{
Effects of a food product (based on Daucus carota) and education based on traditional Persian medicine on female sexual dysfunction: a randomized clinical trial
}

Tahereh Molkara ${ }^{1,2}$, Farideh Akhlaghi ${ }^{3}$, Mohammad Arash Ramezani $^{4}$, Roshanak Salari ${ }^{5}$, Veda Vakili ${ }^{6}$, Mohammad Kamalinejad ${ }^{7}$, Mohammad Reza Fayyazi Bordbar ${ }^{8}$, Ahmad Ghorbani ${ }^{9}$, Malihe Motavasselian ${ }^{10}$

${ }^{1}$ Ph.D. Student of Persian Medicine, Department of Persian and complementary Medicine, School of Persian and Complementary Medicine, Mashhad University of Medical Sciences, Mashhad, Iran

${ }^{2}$ Student Research Committee, School of Persian and Complementary Medicine, Mashhad University of Medical Sciences, Mashhad, Iran

${ }^{3}$ Gynecologist, Professor, Department of Obstetrics and Gynecology, Faculty of Medicine, Mashhad University of Medical Sciences, Mashhad, Iran

${ }^{4}$ Assistant Professor of Sexual Health and Sex therapy-Family and Couple Therapy, Family Research Institute, Shahid Beheshti University, Tehran, Iran

${ }^{5}$ Ph.D. of Drug Control, Assistant Professor, Department of Clinical Persian Pharmacy, School of Persian and Complementary Medicine, Mashhad University of Medical Sciences, Mashhad, Iran

${ }^{6}$ Community Medicine Specialist, Assistant Professor, Department of Community Medicine, Faculty of Medicine, Mashhad University of Medical Sciences, Mashhad, Iran

${ }^{7}$ M.Sc., Researcher, School of Pharmacy, Shahid Beheshti University of Medical Sciences, Tehran, Iran

${ }^{8}$ Psychiatrist, Professor, Psychiatry and Behavioral Sciences Research Center, Mashhad University of Medical Sciences, Mashhad, Iran

9 Ph.D. of Physiology, Associate Professor, Pharmacological Research Center of Medicinal Plants, Mashhad University of Medical Sciences, Mashhad, Iran

${ }^{10}$ Ph.D. of Persian Medicine, Assistant Professor, Department of Persian and Complementary Medicine, School of Persian and Complementary Medicine, Mashhad University of Medical Sciences, Mashhad, Iran

\section{Type of article: Original}

\begin{abstract}
Background: Globally, female sexual dysfunction is a serious concern based on negative family and social consequences, high side effects of medications and lack of effective treatment. Thus, the evaluation of treatment approach for this problem is an important priority for healthcare systems. Sexual life and its related disorders are considered the main aspects of a healthy lifestyle in traditional Persian medicine (TPM).

Objective: The present study aimed to determine and compare the effects of food products containing Daucus carota, TPM-based training program, and a combination of these two interventions on the improvement of female sexual dysfunction.

Methods: This randomized clinical trial was conducted on 96 women with sexual dysfunction based on the Diagnostic and Statistical Manual of Mental Disorders (DSM-5®), aged 18-35 years who referred to the Gynecology Clinic of Mashhad University of Medical Sciences, Mashhad, Iran, during 2016 and 2017. The patients were randomly divided into three groups $(\mathrm{n}=32)$ and received the intervention over an eight-week period. The first group was provided with TPM-based sexual health training, the second group received $30 \mathrm{~g}$ of a traditional food product (wild carrot halva: mixed Daucus carota and several herbs with honey) on a daily basis, and the third group received a combination of this traditional food product plus education. Data analysis was
\end{abstract}

\section{Corresponding author:}

Assistant Professor Dr. Malihe Motavasselian, Department of Persian and Complementary Medicine, Mashhad University of Medical Sciences, Mashhad, Iran.

Tel: +98.5138848930, Fax:+98.5138829279, Email: m_motevasselian@yahoo.com

Received: August 28, 2017, Accepted: October 26, 2017, Published: April 2018

iThenticate screening: October 23, 2017, English editing: January 15, 2018, Quality control: February 12, 2018

This article has been reviewed / commented by six experts

(C) 2018 The Authors. This is an open access article under the terms of the Creative Commons Attribution-NonCommercialNoDerivs License, which permits use and distribution in any medium, provided the original work is properly cited, the use is non-commercial and no modifications or adaptations are made. 
performed using Chi square test, repeated measures ANOVA, two-way ANOVA, ANCOVA, post hoc Bonferroni, Friedman and Wilcoxon signed-rank test in SPSS version 11.5.

Results: According to the results of this study, there was a significant difference in terms of sexual desire $(p=0.002)$, lubrication $(p=0.002)$, orgasm $(p=0.004)$ and pain $(p<0.001)$ after eight weeks of the intervention among the three groups.

Conclusion: The use of two interventions of TPM including a food product containing Daucus carota and this product with TPM-based education improved desire, arousal, lubrication, orgasm, satisfaction and pain in females with sexual dysfunction. Furthermore, TPM-based education alone, led to the improvement of all domains of sexual dysfunction, except for pain in the females with sexual dysfunction.

Trial registration: The trial was registered at the Iranian Registry of Clinical Trials with the IRCT ID: IRCT2015122425681N1).

Funding: The present study was supported by a grant from the Research Council, Mashhad University of Medical Sciences, Mashhad, Iran (ref. no.: 941503).

Keywords: Daucus Carota, Herbal Medicine, Phytotherapy; Libido, Sex Education, Traditional Persian Medicine

\section{Introduction}

Sexual dysfunction is a major problem that may be reported by many individuals or couples during any stage of life. Based on the Diagnostic and Statistical Manual of Mental Disorders, Fifth Edition (DSM-5), this construct is defined as a problem taking place during the sexual response cycle preventing the experience of satisfaction from sexual activity by the individual or couple (1). Sexual dysfunction can have a great impact on the quality of sexual life in young couples (2). Sexual dysfunction is common in both genders, and it has been reported to be higher in the female population (3). Accordingly, this has been also confirmed by several studies conducted in the USA (4), reporting a sexual dysfunction prevalence rate of $40 \%$ in females (5). In Iran, the prevalence of sexual dysfunction has been reported to be $30 \%$ in this population (6). However, it seems that the rate of sexual dysfunction among females has been underestimated in Iran due to cultural limitations, shame, and attitude toward intercourse (7). Psychological and physiological factors play an important role in the sexual function. The main symptoms of sexual dysfunction, such as decreased libido, vaginal dryness, pain, numbness in the genital area, decreased arousal, and orgasm dysfunction, occur due to vascular, neurological, hormonal, and psychological disorders (8). In addition, unpleasant intercourse, psychological disorders, income and social status, and infertility can affect sexual dysfunction $(9,10)$. According to the literature, sexual dysfunction plays a key role in the women's self-esteem, interpersonal relationships, and quality of life $(6,11)$. Based on TPM, sexual life and intercourse are considered as the main aspects of a healthy lifestyle (12) which lead to family binding, survival of generations, and individuals' well-being $(13,14)$. Health maintenance recommendations and measures are the basis of TPM books. These books underscore the importance of pleasure during sexual activity and contain many recommendations about the optimization of sexual intercourse. They also repeatedly discuss the complications caused by infrequent or having no sexual intercourse $(13,14)$. The problems caused by sexual dysfunction have received special attention in the traditional Persian books to the extent that a full chapter of the Canon of Medicine (1025 AD) written by Avicenna is dedicated to the description of libido, its disorders, and treatment of sexual problems (13). In addition, some traditional Persian books, including Lezat al-vesal (15) and Tuhfat al-Molouk (16) have covered such sexual issues as sexual intercourse and the ways of improving the sex life. Some herbal medicines, such as Bindii or Tribulus terrestris are proposed to be effective in the improvement of libido and sex drive in the Canon of Medicine $(13,17)$. Psychotherapy and pharmacotherapy are two main methods for the treatment of female sexual dysfunction (18). The effectivness of some drugs, such as estrogen, methyl testostron (18), bupropion (19), saffron (20), and Tribulus terrestris (7), on the treatment of sexual dysfunction is demonstrated. However, the Food and Drug Administration Agency (FDA) has recommended no foods or drugs as the effective agents for the treatment of sexual disorders in females (21). Daucus carota is known as a useful vegetable, which belongs to the family of Umbelliferae or Apiaceaeis. This plant has been used in traditional medicine (1) since it has therapeutic effects on a wide range of diseases Daucus carota is a great source of antioxidant vitamins, especially beta-carotene, which can enhance the level of sexual function (22). Beta-carotene leads to elevated levels of sex hormones (23); therefore, we chose this plant to evaluate its effects on sexual function in females. To the extent of the researchers' knowledge, there is no study investigating the effect of Daucus carota on the human sex drive. Therefore, this study was performed to assess the effectiveness of a food product containing Daucus carota, a type of education (which was based on TPM) (17), and a combination of these two approaches on the improvement of sexual function in females with sexual dysfunction. 


\section{Material and Methods}

\subsection{Study design and setting}

This randomized clinical trial was conducted during eight weeks on females of reproductive age (i.e., 18-35 years) with sexual dysfunction. The patients were referred to the Obstetrics and Gynecology Ward of Om al-Banin Hospital and Traditional Medicine Clinic of Mashhad University of Medical Sciences, Mashhad, Iran, from June 2016 to February 2017 and selected using convenience sampling method. After considering the inclusion and exclusion criteria, 96 women were enrolled and divided into three groups (32 people in each group). The stages of sample selection are shown in Figure 1.

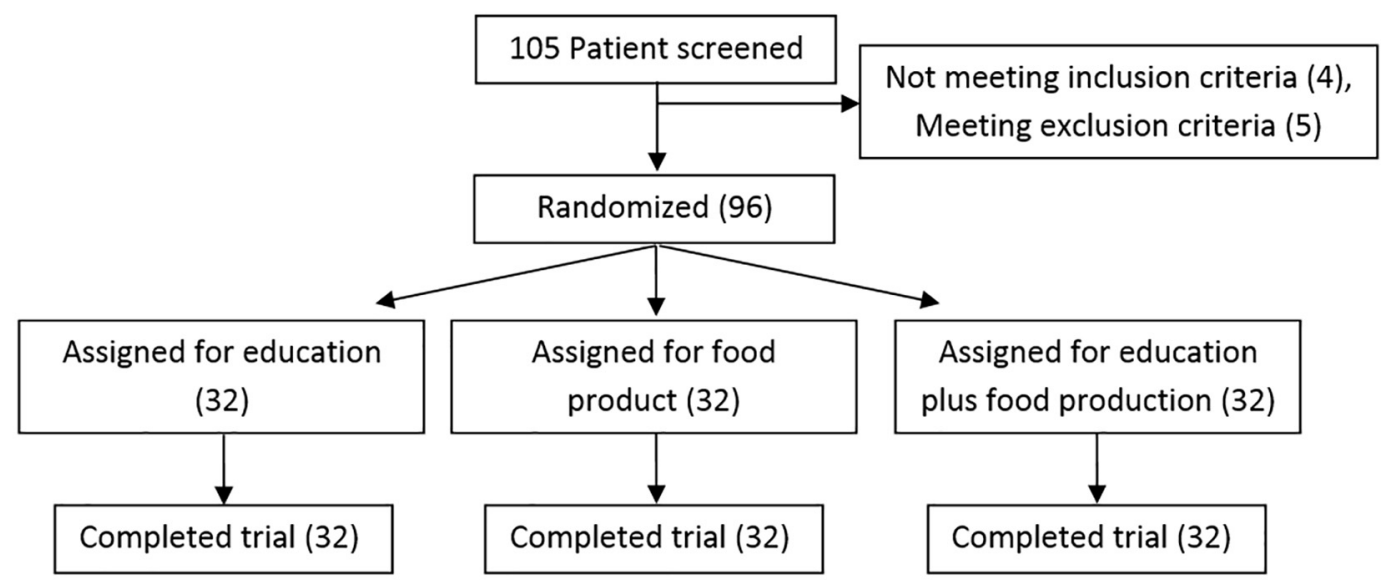

Figure 1. CONSORT Flow Diagram of the study

\subsection{Ethical considerations}

This study was derived from a clinical trial, confirmed by the Ethics Committee of Mashhad University of Medical Sciences (Ref. no.: IR.MUMS.REC.1395.65) and recorded in the clinical trial center (IRCT ID: IRCT2015122425681N1). Before gathering the data, informed consent was obtained from all the subjects and all of them were assured of the confidentiality of the data. Also, the objectives of the study were explained to all the participants. In the next step, personal information forms were completed by all the participants. The participants were ensured that they could withdraw from the study at any stage.

\subsection{Participants}

The inclusion criteria were: 1) a history of sexual dysfunction for more than six months, 2) normal gynecologic and breast exam, and 3) spending at least 21 days a month with the husband. The exclusion criteria were: 1) pregnancy and lactation, 2) having a chronic disease, 3) husbands' sexual dysfunction, 4) couple's addiction to alcohol or drugs, 5) filing for divorce, 6) the use of drugs affecting the sexual function, 7) any medical side effects and hemodynamic disorder, and 8) not consuming the food product for more than three consecutive times.

\subsection{Study design}

After examining the participants to ensure physical and mental health, they were randomly divided into three groups using the Power Analysis and Sample Size (PASS) software, and received the intervention for eight weeks. The first group received behavioral principle training, which was based on TPM, and the second group consumed $30 \mathrm{~g}$ of a traditional food product containing Daucus carota on a daily basis. Furthermore, the third group received a combination of the two prior to interventions (i.e., a traditional food product plus behavioral training). The intervention was started from the second day of menstruation. For the purpose of the study, all the women were visited by a gynecologist. The presence of sexual dysfunction due to any gynecological diseases and anatomic causes were rejected in this study. In addition, breast examination, and if necessary, Pap smear, uterus, and ovary ultrasound were obtained from all the samples. Subsequently, the samples were referred to the traditional medicine clinic to arrange a medical record for each case based on TPM by an assistant of traditional medication. The demographic information as well as the details and quality of couples' relationships were collected. In addition, the factors related to the stability of marriage were assessed in all samples. The participants' sexual function was determined by using a normalized female sexual functioning index (FSFI) Persian version. The validity and 
reliability of this index were assessed in a study conducted by Mohammadi et al. (24). According to this scale, a total score of 28 or less represents the risk of sexual dysfunction.

\subsection{Intervention}

\subsubsection{Training intervention}

In this study, we included the health maintenance recommendations derived from TPM books, such as Al Qanun Fi Al-Tibb (13) in the training sessions. These recommendations covered several basic principles related to sexual function, such as time of intercourse, nutrition, drinks, wearing perfume, exercise, movement and rest before and after intercourse, foreplay, hygiene, use of lubricant, sleeping and waking, mental calmness during intercourse (13). The participants were informed not to have sexual intercourse during satiety, hunger, excessive sweating, and menstruation or after phlebotomy and cupping. The trainings were presented to groups by a physician. Each group contained four participants. These trainings were repeated every two weeks (i.e., pre-intervention, and two, four, and six weeks post-intervention). They were also recommended to have nutritious food, such as chickens' egg, red meat $(100 \mathrm{~g})$, as well as cooked beans and peas $(50 \mathrm{~g})$ every other day. In addition, the participants were instructed not to drink, bathe with cold water, or play extreme sports after sexual intercourse. Sexual intercourse was encouraged to be performed in a moderate temperature. Moreover, resting was suggested before and after sexual intercourse. The patients were trained not to have sexual intercourse at the time of severe anger, happiness, sadness, or shame. The use of refreshing aromas (i.e., rose and apple), preservation of personal hygiene of the genital area, and the application of sole foot massage with almond oil before sexual intercourse were recommended to be performed every night for $5 \mathrm{~min}$. Sexual intercourse was suggested to be performed two or three times a week. The participants were also informed about the importance of foreplay (25). Additionally, they were recommended not to use carrot juice or carrot jam.

\subsubsection{Food product intervention}

In the second group, $420 \mathrm{~g}$ of the food product was administered in 28 packages ( $15 \mathrm{~g}$, twice a day) every two weeks for eight weeks, commencing from the second day of the menstruation. The instruction for the food product use was indicated on the package. The dosage was determined using traditional medicine books and consulting with several professors. In addition, the patients were orally informed to start the food product consumption on the second day of menstruation and report it to the physician through a phone call. The participants referred to the clinic after 14 days to determine the possible side effects and receive the food product to continue the treatment. The patients could easily access their physician during office hours, or make phone calls any time. The subjects were excluded from the study if they showed hypersensitivity, or if they did not use the food product more than three consecutive times. They could leave the project at any time that they wished.

\subsubsection{Food product preparation}

In this study, a traditional food product (wild carrot halva), which was a combination of Daucus carota and its seed, Amygdalus Communis L., Pistacia Vera and Crocus Sativus were provided from the local market in consultation with an expert botanist. This compound was prepared based on the instructions of traditional medicine books and consultation with professionals in pharmacology and medicinal herbs in the laboratory of the School of Traditional Medicine at Mashhad University of Medical Sciences. Based on the Great Qarabadin, to prepare $1 \mathrm{~kg}$ of this food product, we used $300 \mathrm{~g}$ Daucus carota, $210 \mathrm{~g}$ honey, $90 \mathrm{~g}$ rock candy, $1 \mathrm{~g}$ saffron, $300 \mathrm{~g}$ almond, 60 pistachios, $30 \mathrm{~g}$ seed of Daucus carota, $150 \mathrm{ml}$ Damask rose extract, $36 \mathrm{~g}$ wheat flour, and $300 \mathrm{ml}$ water. In the first step, $300 \mathrm{~g}$ Daucus carota was peeled and grated, and then cooked in $150 \mathrm{ml}$ water, so that the water was completely evaporated and the cooked Daucus carota was mashed. Afterwards, almond, pistachios, and wheat flour were roasted together, and then sieved. In consultation with experts, $30 \mathrm{~g}$ Daucus carota seed was boiled in $150 \mathrm{ml}$ water for 3 min and screened by a very fine filter. Afterwards, the honey was added to the mashed Daucus carota and mixed under low temperature, and then the hydro extract of the boiled Daucus carota seeds were added to this mixture and temperature repeatedly. The powdered saffron was brewed in $150 \mathrm{ml}$ Damask rose extract for $15 \mathrm{~min}$; subsequently, the crushed candy was added to this mixture. The combination of almond and pistachios was added to the mixture of honey and Daucus carota. Subsequently, the saffron and candy solution were added. The mixture was kept in a low degree for five minutes.

\subsubsection{Standardization of the food product}

A sample of the food product $(30 \mathrm{~g})$ was suspended in $70 \%$ ethanol $(200 \mathrm{ml})$ and incubated for $72 \mathrm{~h}$ at $40{ }^{\circ} \mathrm{C}$ with gentle shaking (26). Then, the extract was filtered through $250 \mu \mathrm{m}$ mesh and centrifuged for $10 \mathrm{~min}$ at $2000 \mathrm{rpm}$. The extract was dried on a water bath $\left(40{ }^{\circ} \mathrm{C}\right)$ to remove the solvent, and the residue was used for standardization. The hydroalcoholic extract of the food product was standardized based on its total phenol content using FolinCiocalteu method. The extract (20 $\mu \mathrm{L}$ of $10 \mathrm{mg} / \mathrm{mL})$ or gallic acid $(20 \mu \mathrm{L}$ of $0,50,100,150,250$, and $500 \mathrm{mg} / \mathrm{L})$ were mixed with Folin-Ciocalteu reagent $(100 \mu \mathrm{L})$ and sodium carbonate solution $(300 \mu \mathrm{L}, 1 \mathrm{M})$. The volume was 
adjusted to $2 \mathrm{~mL}$ with deionized water and after $2 \mathrm{~h}$, the absorbance was measured by spectrometer at $765 \mathrm{~nm}$. The standard curve was prepared for gallic acid, and the total phenol content of the food product extract was expressed as milligram of gallic acid equivalents (27).

\subsubsection{Combined intervention}

A combination of both food product and behavioral principles training interventions was presented to the individuals in the third group for eight weeks. The FSFI was filled out by all the participants in three stages, including before the intervention as well as four, and eight weeks after the intervention.

\subsection{Statistical analysis}

The data were analyzed using the Chi square test, repeated measures ANOVA, two-way ANOVA, post hoc Bonferroni, Friedman, ANCOVA, and Wilcoxon signed-rank test through the SPSS version 11.5. The p-value less than 0.05 was considered statistically significant.

\section{Results}

The demographic data is outlined in Table 1. According to the obtained results of this study, all data of sexual function domains had no normal distribution, expect total score. The abnormal distribution was assessed using the Kolmogorov-Smirnov and Shapiro-Wilk tests. The mean values of sexual function domains are shown in Table 2. The results of six domains of these women's sexual function are as follows:

Table1. Comparison of Demographic characteristic among study groups

\begin{tabular}{|c|c|c|c|c|c|c|}
\hline \multicolumn{2}{|l|}{ Variables } & \multicolumn{3}{|c|}{ Group; n (\%) } & \multirow{2}{*}{$\begin{array}{l}\text { Total; n } \\
\text { (\%) }\end{array}$} & $\mathrm{p}$-value \\
\hline \multirow[t]{7}{*}{ Education } & Illiterate & $\begin{array}{l}\text { Education } \\
0(0.0)\end{array}$ & \begin{tabular}{|l|}
$\begin{array}{l}\text { Food } \\
\text { production }\end{array}$ \\
$1(3.2)$ \\
\end{tabular} & $\begin{array}{l}\text { Education plus } \\
\text { Food production } \\
0(0.0)\end{array}$ & & \multirow{7}{*}{$\begin{array}{l}0.763 \\
\text { (Kruskal- } \\
\text { Wallis) }\end{array}$} \\
\hline & Primary school & $4(12.5)$ & $2(6.5)$ & $3(9.4)$ & $9(9.5)$ & \\
\hline & Junior high school & $3(9.4)$ & $4(12.9)$ & $3(9.4)$ & $10(10.5)$ & \\
\hline & High school diploma & $14(43.8)$ & $12(38.7)$ & $19(59.4)$ & $45(47.4)$ & \\
\hline & Associate Degree & $8(25)$ & $8(25.8)$ & $4(12.5)$ & $20(21.1)$ & \\
\hline & Bachelor and above & $3(9.4)$ & $4(12.9)$ & $3(9.4)$ & $10(10.5)$ & \\
\hline & Total & $32(100)$ & $31(100)$ & $32(100)$ & $95(100)$ & \\
\hline \multirow{6}{*}{$\begin{array}{l}\text { Occupational } \\
\text { status }\end{array}$} & Unemployed & $2(6.9)$ & $3(10.3)$ & $1(3.3)$ & $6(6.8)$ & \multirow{6}{*}{$\begin{array}{l}0.888 \text { (Mont } \\
\text { Carlo Chi } \\
\text { square) }\end{array}$} \\
\hline & Employed & $3(10.3)$ & $4(13.8)$ & $4(13.3)$ & $11(12.5)$ & \\
\hline & Student & $2(6.9)$ & $3(10.3)$ & $1(3.3)$ & $6(6.8)$ & \\
\hline & Housewife & $20(69)$ & $15(51.7)$ & $21(70)$ & $56(63.6)$ & \\
\hline & Self- employed & $2(6.9)$ & $4(13.8)$ & $3(10)$ & $9(10.2)$ & \\
\hline & Total & $29(100)$ & $29(100)$ & $30(100)$ & $88(100)$ & \\
\hline \multirow{3}{*}{$\begin{array}{l}\text { Place of } \\
\text { residence }\end{array}$} & Urban & $31(100)$ & $31(96.9)$ & $31(100)$ & 94 (98.9) & \multirow{3}{*}{$\begin{array}{l}1.000 \text { (Mont } \\
\text { Carlo Chi } \\
\text { square) }\end{array}$} \\
\hline & Rural & $0(0.0)$ & $1(3.1)$ & $0(0.0)$ & $1(1.1)$ & \\
\hline & Total & $31(100)$ & $32(100)$ & $31(100)$ & $95(100)$ & \\
\hline \multirow[t]{3}{*}{ Housing status } & Landlord & $8(27.6)$ & $20(64.5)$ & $16(51.6)$ & $44(48.4)$ & \multirow{3}{*}{$\begin{array}{l}0.015 \text { (Chi } \\
\text { square) }\end{array}$} \\
\hline & Tenant & $21(72.4)$ & $11(35.5)$ & $15(48.4)$ & $47(51.6)$ & \\
\hline & Total & $29(100)$ & $31(100)$ & $31(100)$ & $91(100)$ & \\
\hline \multirow{3}{*}{$\begin{array}{l}\text { Alcohol } \\
\text { consumption }\end{array}$} & Spouse & $4(12.5)$ & $0(0.0)$ & $3(10)$ & $7(7.4)$ & \multirow{3}{*}{$\begin{array}{l}0.174 \text { (Mon } \\
\text { Carlo Chi } \\
\text { square) }\end{array}$} \\
\hline & Neither & $28(87.5)$ & $32(100)$ & $27(90)$ & 87 (92.6) & \\
\hline & Total & $32(100)$ & $32(100)$ & $30(100)$ & $94(100)$ & \\
\hline \multirow[t]{4}{*}{ Smoking } & Spouse & $7(21.9)$ & $7(21.9)$ & $7(21.9)$ & $21(21.9)$ & \multirow{4}{*}{$\begin{array}{l}1.000 \text { (Mon } \\
\text { Carlo Chi } \\
\text { square) }\end{array}$} \\
\hline & Both & $0(0.0)$ & $0(0.0)$ & $1(3.1)$ & $1(1.0)$ & \\
\hline & Neither & $25(78.1)$ & $25(78.1)$ & $24(75)$ & $74(77.1)$ & \\
\hline & Total & $32(100)$ & $32(100)$ & $32(100)$ & $96(100)$ & \\
\hline \multirow[t]{5}{*}{ Marital status } & Women & $1(3.2)$ & $0(0.0)$ & $2(6.5)$ & $3(3.2)$ & \multirow{5}{*}{$\begin{array}{l}0.609 \text { (Mon } \\
\text { Carlo Chi } \\
\text { square) }\end{array}$} \\
\hline & Spouse & $1(3.2)$ & $0(0.0)$ & $1(3.2)$ & $2(2.1)$ & \\
\hline & Both & $1(3.2)$ & $0(0.0)$ & $1(3.2)$ & $2(2.1)$ & \\
\hline & Neither & $28(90.3)$ & $32(100)$ & $27(87.1)$ & 87 (92.6) & \\
\hline & Total & $31(100)$ & $0(0.0)$ & $31(100)$ & $94(100)$ & \\
\hline
\end{tabular}


Table 2. Comparison of Mean values of sexual function domains among study groups

\begin{tabular}{|c|c|c|c|c|c|}
\hline $\begin{array}{l}\text { Domains of sexual } \\
\text { function }\end{array}$ & Stages & $\begin{array}{l}\text { Education plus } \\
\text { food product }^{1}\end{array}$ & $\begin{array}{l}\text { Food } \\
\text { product }^{1}\end{array}$ & Education $^{1}$ & p-value \\
\hline \multirow[t]{3}{*}{ Desire } & Pre-intervention & $2.9 \pm 0.8$ & $2.6 \pm 0.8$ & $2.8 \pm 0.8$ & 0.313 \\
\hline & After four weeks & $3.4 \pm 0.8$ & $3.2 \pm 0.8$ & $3.4 \pm 0.7$ & 0.327 \\
\hline & After eight weeks & $4.4 \pm 0.4$ & $4.1 \pm 0.6$ & $3.9 \pm 0.6$ & 0.002 \\
\hline \multirow[t]{3}{*}{$\begin{array}{l}\text { Mean paired difference of } \\
\text { desire }\end{array}$} & $\begin{array}{l}\text { Pre-intervention and four week after } \\
\text { treatment }\end{array}$ & $0.5 \pm 0.7$ & $0.6 \pm 0.8$ & $0.5 \pm 0.8$ & 0.98 \\
\hline & Four and eight weeks difference & $1 \pm 0.9$ & $1 \pm 0.8$ & $0.5 \pm 0.9$ & 0.19 \\
\hline & Eight and Pre-intervention & $1.6 \pm 0.7$ & $1.6 \pm 0.9$ & $1.1 \pm 0.8$ & 0.024 \\
\hline \multirow[t]{3}{*}{ Arousal } & Pre-intervention & $3 \pm 0.8$ & $2.9 \pm 0.8$ & $3.4 \pm 1$ & 0.007 \\
\hline & After four weeks & $3.6 \pm 0.8$ & $3.7 \pm 0.6$ & $3.8 \pm 0.9$ & 0.757 \\
\hline & After eight weeks & $4.7 \pm 0.6$ & $4.5 \pm 0.7$ & $4.3 \pm 0.8$ & 0.213 \\
\hline \multirow[t]{3}{*}{$\begin{array}{l}\text { Mean paired difference of } \\
\text { arousal }\end{array}$} & $\begin{array}{l}\text { Pre-intervention and four week after } \\
\text { treatment }\end{array}$ & $0.7 \pm 0.8$ & $0.8 \pm 0.8$ & $0.4 \pm 0.8$ & 0.15 \\
\hline & Four and eight weeks & $1.1 \pm 1$ & $0.8 \pm 0.6$ & $0.5 \pm 0.9$ & 0.123 \\
\hline & Eight and Pre-intervention & $1.7 \pm 1$ & $1.7 \pm 1$ & $0.9 \pm 1$ & 0.002 \\
\hline \multirow[t]{3}{*}{ Orgasm } & Pre-intervention & $2.8 \pm 0.8$ & $3.2 \pm 1.1$ & $3.2 \pm 0.9$ & 0.087 \\
\hline & After four weeks & $3.7 \pm 0.9$ & $3.8 \pm 1$ & $3.6 \pm 1.1$ & 0.902 \\
\hline & After eight weeks & $5 \pm 0.6$ & $4.6 \pm 1$ & $4.3 \pm 0.9$ & 0.004 \\
\hline \multirow[t]{3}{*}{$\begin{array}{l}\text { Mean paired difference of } \\
\text { orgasm }\end{array}$} & $\begin{array}{l}\text { Pre-intervention and four week after } \\
\text { treatment }\end{array}$ & $0.9 \pm 1$ & $0.6 \pm 1.1$ & $0.4 \pm 1$ & 0.11 \\
\hline & Four and eight weeks difference & $1.3 \pm 1$ & $0.8 \pm 0.8$ & $0.7 \pm 1.2$ & 0.023 \\
\hline & Eight and Pre-intervention & $2.2 \pm 0.9$ & $1.4 \pm 1$ & $1.1 \pm 0.9$ & $<0.001$ \\
\hline \multirow[t]{3}{*}{ Lubrication } & Pre-intervention & $3.7 \pm 0.7$ & $3.8 \pm 0.9$ & $3.8 \pm 1$ & 0.794 \\
\hline & After four weeks & $4.3 \pm 0.9$ & $4.6 \pm 0.8$ & $4.2 \pm 0.9$ & 0.172 \\
\hline & After eight weeks & $5.3 \pm 0.5$ & $5.2 \pm 0.6$ & $4.6 \pm 0.9$ & 0.002 \\
\hline \multirow[t]{3}{*}{$\begin{array}{l}\text { Mean paired difference of } \\
\text { lubrication }\end{array}$} & $\begin{array}{l}\text { Pre-intervention and four week after } \\
\text { treatment }\end{array}$ & $0.6 \pm 1$ & $0.8 \pm 1$ & $0.4 \pm 1$ & 0.24 \\
\hline & Four and eight weeks difference & $1 \pm 0.8$ & $0.7 \pm 0.6$ & $0.4 \pm 0.7$ & 0.006 \\
\hline & Eight and Pre-intervention & $1.6 \pm 0.8$ & $1.0 \pm 0.8$ & $0.8 \pm 1.1$ & 0.207 \\
\hline \multirow[t]{3}{*}{ Satisfaction } & Pre-intervention & $3.5 \pm 0.9$ & $3.7 \pm 1$ & $4 \pm 1.1$ & 0.204 \\
\hline & After four weeks & $4.3 \pm 0.9$ & $4.4 \pm 1$ & $4.1 \pm 1$ & 0.616 \\
\hline & After eight weeks & $5.2 \pm 0.5$ & $5 \pm 0.8$ & $4.9 \pm 0.8$ & 0.202 \\
\hline \multirow[t]{3}{*}{$\begin{array}{l}\text { Mean paired difference of } \\
\text { satisfaction }\end{array}$} & $\begin{array}{l}\text { Pre-intervention and four week after } \\
\text { treatment }\end{array}$ & $0.8 \pm .1 .1$ & $0.7 \pm 0.8$ & $1 \pm 0.9$ & 0.004 \\
\hline & Four and eight weeks & $0.9 \pm 0.9$ & $0.7 \pm 0.8$ & $0.8 \pm 1.1$ & 0.504 \\
\hline & Eight and Pre-intervention & $1.7 \pm 1$ & $1.3 \pm 1$ & $0.9 \pm 1.3$ & 0.017 \\
\hline \multirow[t]{3}{*}{ Pain } & Pre-intervention & $3.7 \pm 1.2$ & $4 \pm 1.2$ & $4 \pm 1.1$ & 0.419 \\
\hline & After four weeks & $4.3 \pm 1.1$ & $4.4 \pm 1.2$ & $4.2 \pm 1$ & 0.741 \\
\hline & After eight weeks & $5.3 \pm 0.7$ & $4.9 \pm 1$ & $4.2 \pm 1.1$ & $<0.001$ \\
\hline \multirow[t]{3}{*}{$\begin{array}{l}\text { Mean paired difference of } \\
\text { pain }\end{array}$} & $\begin{array}{l}\text { Pre-intervention and four week after } \\
\text { treatment }\end{array}$ & $0.6 \pm 1.2$ & $0.4 \pm 1.2$ & $0.1 \pm 1$ & 0.252 \\
\hline & Four and eight weeks & $1 \pm 1.2$ & $0.5 \pm 0.9$ & $1 \pm 1.1$ & 0.008 \\
\hline & Eight and Pre-intervention & $1.6 \pm 1.2$ & $0.9 \pm 1.3$ & $0.2 \pm 1.2$ & $<0.001$ \\
\hline \multirow[t]{3}{*}{ Total sexual function } & Pre-intervention & $19.5 \pm 3.4$ & $20 \pm 3.8$ & $21.2 \pm 3.8$ & 0.151 \\
\hline & After four weeks & $23.7 \pm 4$ & $23.9 \pm 3.9$ & $23.3 \pm 3.3$ & 0.77 \\
\hline & After eight weeks & $29.8 \pm 2.2$ & $28.6 \pm 2.9$ & $26.2 \pm 3.4$ & $<0.001$ \\
\hline \multirow[t]{3}{*}{$\begin{array}{l}\text { Mean paired difference of } \\
\text { total sexual function }\end{array}$} & $\begin{array}{l}\text { Pre-intervention and four week after } \\
\text { treatment }\end{array}$ & $4.3 \pm 3.5$ & $3.9 \pm 3.3$ & $2.1 \pm 3.3$ & 0.026 \\
\hline & Four and eight weeks & $4.6 \pm 4$ & $4.6 \pm 2.9$ & $2.8 \pm 3$ & $<0.001$ \\
\hline & Eight and Pre-intervention & $10.6 \pm 3.8$ & $8.6 \pm 3.5$ & $5 \pm 3.6$ & $<0.001$ \\
\hline
\end{tabular}

1: Data is presented as Mean $\pm \mathrm{SD}$ 


\subsection{Desire}

The three groups were not significantly different in terms of sexual desire before the initiation of the intervention $(p=0.31)$ and four weeks after treatment $(p=0.32)$. However, a significant difference was observed eight weeks after the intervention in this regard $(\mathrm{p}=0.002)$. The paired comparison of the mean difference in terms of sexual desire showed no significant difference between the food product and the food product plus education groups in this regard. The score of sexual desire was higher in two groups of food product and food product plus education, compared to that of the education group. The evaluation of the changes of sexual function in terms of desire in education $(\mathrm{p}<0.001)$, food product $(\mathrm{p}<0.001)$, and education plus food product $(\mathrm{p}<0.001)$ groups demonstrated a significant difference among the three stages of the intervention. The paired comparison of different stages showed that the desire domain increased in each stage, compared to the previous stage.

\subsection{Arousal}

No significant differences were observed among the three groups with respect to arousal score before treatment $(p=0.07)$ and four $(p=0.75)$ and eight $(p=0.21)$ weeks after the intervention. The evaluation of the changes of sexual function in terms of arousal in education $(p<0.001)$, food product $(p<0.001)$, and education plus food product $(p<0.001)$ groups revealed a significant difference among the three stages of the study in this regard. The arousal domain was also found to increase in each stage as compared to the previous one.

\subsection{Orgasm}

The three groups were not significantly different in terms of orgasm before treatment $(p=0.08)$ and four weeks after the intervention $(p=0.902)$. However, a significant difference was noted at eight weeks after the intervention $(p=0.004)$. In addition, the food product plus training group obtained the highest orgasm scores at eight weeks postintervention, while the training group had the lowest score in this respect. There was a significant difference among the three stages of the intervention regarding the changes of orgasm score in the education $(p<0.001)$, food product $(p<0.001)$, and education plus food product $(\mathrm{p}<0.001)$ groups. In other words, the orgasm score increased in each stage, compared to the previous stage.

\subsection{Lubrication}

No significant differences were found among the three groups in terms of lubrication before the treatment $(p=0.79)$ and four weeks after the treatment $(\mathrm{p}=0.17)$. We observed a significant difference in lubrication score at eight weeks after the intervention $(\mathrm{p}=0.002)$. The score of the lubrication domain was higher in the food product plus education group, compared to that in the education group. The evaluation of the lubrication changes in the education $(\mathrm{p}<0.001)$, food product $(\mathrm{p}<0.001)$, and education plus food product $(\mathrm{p}<0.001)$ groups indicated a significant difference among the three stages of the intervention in this regard. This indicated that the desire domain improved in each stage, compared to the previous one.

\subsection{Sexual satisfaction}

No significant difference was observed among the three groups regarding sexual satisfaction at the pre-treatment stage $(p=0.204)$, and four $(p=0.61)$ and eight $(p=0.202)$ weeks after the intervention. The evaluation of the changes of sexual satisfaction score in the education $(p<0.001)$, food product $(p<0.001)$, and education plus food product $(p<0.001)$ groups showed a significant difference among the three stages of the study. The study of this variable in the food product and food product plus education groups revealed that it increased in each stage, compared to the previous one. However, in the case of the education group, this enhancement was observed just eight weeks after the intervention.

\subsection{Pain}

There was no significant difference among the three groups before the intervention $(p=0.41)$ and four weeks after treatment $(p=0.74)$ in terms of pain. Nevertheless, a significant difference was observed eight weeks after the intervention. Additionally, paired comparison of different stages demonstrated that the pain scores were higher at eight weeks after the intervention in the food product plus education group than those in the other groups. There was a significant difference among the three stages of the intervention in the pain scores of the food product ( $\mathrm{p}<0.001$ ) and education plus food product $(\mathrm{p}<0.001)$ groups. Nonetheless, in the education group, no significant difference was observed in this regard $(\mathrm{p}=0.15)$. The paired comparison of different stages in the food product and education plus food product groups showed that the pain scores increased in each stage, compared to the previous one. 


\subsection{Total scores}

There was no significant difference among the three groups before the treatment $(\mathrm{p}=0.15)$ and four weeks after the treatment $(\mathrm{p}=0.77)$ in terms of total sexual function score. However, a significant difference was observed eight weeks after the intervention in this respect $(\mathrm{p}<0.001)$. The mean total sexual function score eight weeks postintervention was higher in the food product plus education group than those in the other groups. Additionally, there was a significant difference among the three stages of the intervention regarding the changes of the sexual function score in the education $(p<0.001)$, food product $(p<0.001)$, and education plus food product groups $(p<0.001)$. The paired comparison of the different stages of the intervention revealed that the total score of sexual function increased in each stage, compared to the previous one. Finally, successful treatment was observed in $28 \%, 52 \%$, and $74 \%$ of the patients in the education, food product, and food product plus education groups, respectively, indicating a significant difference among the three groups $(\mathrm{p}<0.001)$.

\section{Discussion}

The present study was the first attempt in investigating the effect of a food product containing Daucus carota and education (based on TPM) on the improvement of sexual function among women of reproductive age. According to the results of this study, the use of a food product containing Daucus carota was more effective in the desire, orgasm, sexual satisfaction, and pain domains of the food product and food product plus education groups, compared to those of the education group. However, the lubrication score was not significantly different among the three groups. Although the three interventions improved the sexual function in the females, the food product and education plus food product were found to be more effective in the improvement of sexual function, compared to the education alone. TPM has underscored the necessity of female orgasm and made many recommendations to increase sexual desire. Our study showed that TPM-based training had a positive effect on the improvement of sexual function among women of reproductive age $(13,28)$. Healthy sexuality largely depends on a healthy diet, such as the consumption of vitamin-rich foods (e.g., fresh spices, herbs, fruits, and vegetables) (29). In this study, we recommended the subjects to use nutritious food, such as chickens' eggs and red meat. The effectiveness of the vitamins of eggs and meat on the increase of sexual desire has been demonstrated (30). The sexual behavior of male was improved after the use of mineral supplements, eggs, and green leaves (31). Eskeland et al. used a product containing chickens' eggs to treat decreased sexual desire in males. They showed that this product had a significant positive effect on the frequency of sexual intercourse (32). Furthermore, the benefits of various food groups, such as seeds and nuts, spices (e.g., cinnamon, ginger, and cayenne pepper) on sexual desire have been indicated (30). In addition, cooked beans and peas, have been shown to have a positive effect on the sexual desire (33). TPM has emphasized the importance of foreplay as a main factor in sexual satisfaction. Although foreplay is considered as a key variable to understanding female sexual satisfaction, its duration is not associated with women's consistency of orgasm (34). The effectiveness of exercise on the treatment of orgasmic dysfunction has not been indicated yet. This variable was believed to have no positive effects on the treatment of orgasmic dysfunction in women (35). However, exercise can lead to the reduction of free radicals (36), reactive oxygen species (37), and regulation of blood flow (38); therefore, it can indirectly affect sexual function. Based on TPM, sexual intercourse should be performed in a moderate temperature (39). However, since temperature is only one of the recommendations of TPM and given that there is no study on the relationship of these two variables, we cannot make a general conclusion in this regard. No study has investigated the effect of temperature, cool water bathing, drinking cool water, or other recommended variables on sexual desire. Therefore, it is not possible to obtain a general conclusion and compare these recommendations. However, the effectiveness of these suggestions in sexual intercourse was demonstrated in our study. Our results showed that a food product based on Daucus carota and education plus this food product had comparable effects on all domains of sexual function. There are no similar studies assessing the effect of Daucus carota on sexual activity; however, the positive effects of this plant are suggested in the Persian (14) and Indian (40) traditional medicine books. Some studies have identified the active components of this plant, including volatile oils, steroids, tannins, flavonoids, and carotene, and evaluated its chemical components. Daucus carota has been revealed to have some therapeutic effects on a wide range of diseases, including kidney dysfunction, asthma, inflammation, and leprosy in several studies (41). Furthermore, this vegetable was reported to have anti-infertility properties in females, and the extract of its seed has been revealed to arrest the estrus cycle of adult rats and decrease the weight of ovaries (42). The antioxidants found in carrots are relatively high (43), and its properties can enhance sperm reserves in cauda epididymis (44). Carrot leaves contain remarkable amounts of porphyrins, which have stimulating effects on the pituitary gland, resulting in enhanced sex hormone levels (22). However, it has not been examined on women. Regarding the emphasis of TPM on the effects of Daucus carota on sexual potency in males and its stimulating effects on the menstruation in the females $(14,43)$, we studied the effect of a food product containing Daucus carota on the sexual function of females. Persian medicine has shown that carrots have therapeutic effects on 
human fertility. Accordingly, the benefits of carrots are indicated in the Zakhireh Kharazmshahi book, written by Seyyed-Esmail Jorjani in the 11th century (14). Our study showed that our food product could increase all aspects of sexual function in females with sexual dysfunction. Daucus carota is rich in beta-carotene, which is an antioxidant vitamin protecting both inside and outside of the cells against free radical damage $(22,45,46)$. Beta-carotene is converted into vitamin A in the body, which helps keep the vagina in good shape and leads to increased sex hormones. This anti-oxidant is also found in some plants or vegetables containing pigment, such as sweet potato, tomato (47), and saffron (23). In another study, saffron's positive effect on female sexual dysfunction is also proven (20). Sexual health is a critical issue which directly affects quality of life. The treatment of sexual disorder in the females is very difficult (48). Given the adverse effects of the pharmacological interventions, the use of herbal medicine as a method with fewer complications is more favorable. TPM is developing and providing new therapeutic methods for the treatment of different diseases. Today, there is limited knowledge about the effect of herbal medicine on sexual dysfunction treatment.

\section{Strengths and Limitations}

The strength of this study is its randomization, which leads to the homogeneity of data and control of the underlying and probabilistic factors in the three groups. However, we did not consider the role of interfering factors, which should be considered to interpret our findings. Lack of knowledge about sexual dysfunction and intercourse in Persian culture and absence of spouse were limitations of our study. Also lack of blinding was another limitation of this study. We recommend adopting methods to control these variables and considering some parameters such as nutrition, psychological factors, family, and social conditions in future studies. Moreover, further studies examining the effects of herbal medicine, which is less costly compared to other drugs, and education on different domains of sexual function, are essential.

\section{Conclusions}

As the findings of the present study indicated, TPM-based education led to the improvement of all domains of sexual dysfunction, except for pain in females with sexual dysfunction. The use of a food product containing Daucus carota improved all domains of sexual function in the females. Although education had a positive effect on sexual function, Daucus carota and education plus Daucus carota had more significant effects on the females' sexual dysfunction, compared to that of the education alone.

\section{Acknowledgments:}

We wish to thank the Mashhad University of Medical Sciences for their cooperation in the present study.

\section{Trial registration:}

The trial was registered at the Iranian Registry of Clinical Trials with the IRCT ID: IRCT2015122425681N1).

\section{Funding:}

The present study was supported by a grant from the Research Council, Mashhad University of Medical Sciences, Mashhad, Iran (ref. no.: 941503).

\section{Conflict of Interest:}

There is no conflict of interest to be declared.

\section{Authors' contributions:}

All authors contributed to this project and article equally. All authors read and approved the final manuscript.

\section{References:}

1) Association AP. Diagnostic and Statistical Manual of Mental Disorders (DSM-5®): American Psychiatric Publishing. 2013. doi: 10.1176/appi.books.9780890425596.

2) Hisasue Si, Kumamoto $Y$, Sato $Y$, Masumori N, Horita H, Kato R, et al. Prevalence of female sexual dysfunction symptoms and its relationship to quality of life: a Japanese female cohort study. Urology. 2005; 65(1): 143-8. doi: 10.1016/j.urology.2004.08.003.

3) Laumann EO, Paik A, Rosen RC. Sexual dysfunction in the United States: prevalence and predictors. JAMA. 1999; 281(6): 537-44. doi: 10.1001/jama.281.6.537. PMID: 10022110 
4) Ito TY, Trant AS, Polan ML. A double-blind placebo-controlled study of Argin Max, a nutritional supplement for enhancement of female sexual function. Journal of Sex \&Marital Therapy. 2001; 27(5): 541-9. doi: 10.1080/713846828.

5) Shifren JL, Monz BU, Russo PA, Segreti A, Johannes CB. Sexual problems and distress in United States women: prevalence and correlates. Obstetrics \& Gynecology. 2008; 112(5): 970-8. doi: 10.1097/AOG.0b013e3181898cdb.

6) Safarinejad M. Female sexual dysfunction in a population-based study in Iran: prevalence and associated risk factors. International Journal of Impotence Research. 2006; 18(4): 382-95. doi: 10.1038/sj.ijir.3901440.

7) Akhtari E, Raisi F, Keshavarz M, Hosseini H, Sohrabvand F, Bioos S, et al. Tribulus terrestris for treatment of sexual dysfunction in women: randomized double-blind placebo-controlled study. Daru. 2014; $22(1)$ : 40. doi: 10.1186/2008-2231-22-40. PMID: 24773615, PMCID: PMC4045980.

8) Berman JR, Berman LA, Werbin TJ, Goldstein I. Female sexual dysfunction: anatomy, physiology, evaluation and treatment options. Current opinion in urology. 1999; 9(6): 563-8. doi: 10.1097/00042307199911000-00012. PMID: 10668578.

9) Kadri N, Mchichi Alami K, Mchakra Tahiri S. Sexual dysfunction in women: population based epidemiological study. Archives of women's mental health. 2002; 5(2): 59-63. doi: 10.1007/s00737-0020141-7

10) Bakhtiari A, Basirat Z, Nasiri-Amiri F. Sexual dysfunction in women undergoing fertility treatment in Iran: prevalence and associated risk factors. Journal of reproduction \& infertility. 2016; 17(1): 26. PMID: 26962480, PMCID: PMC4769852.

11) Safarinejad MR, Kolahi AA, Hosseini L. The effect of the mode of delivery on the quality of life, sexual function, and sexual satisfaction in primiparous women and their husbands. The journal of sexual medicine. 2009; 6(6): 1645-67.doi: 10.1111/j.1743-6109.2009.01232.x.

12) Vand FS, Akhtari E. To increase health of intercourse with Iranian Traditional Medicine. History of Medicine Journal. 2016; 5(14): 97-111.

13) Sina I. Al-qanun fi al-tibb [the canon of medicine], in Alaalami Library, Beirut. 2013, Ambassador Ardehal with the assistance of the Faculty of Traditional Medicine, Tehran University of Medical Sciences: Tehran. 389-99.

14) Gorgani Z, Kharazmshahi Zi. Qom. Rehabilitation Institute of natural medicine. 2012; 2.

15) Sekandaripour MAG. Lezat Alvesal. Tehran: Institution of Medical History Studies, Islamic and Complementary Medicine, Iran University of Medical Sciences; 2009.

16) Zeyd -Ibn- heybat- allah- al- Basari. Tuhfat al molouk. Tehran Institute for the Study of Medical History. Islamic Medicine and Supplement of Iran University of Medical Sciences.1999.

17) Aghili MH. Makhzan-al-Advia. Tehran: Tehran University of Medical Sciences. 2009; 328.

18) Davis SR, van Der Mooren M, van Lunsen RH, Lopes P, Ribot J, Rees M, et al. Efficacy and safety of a testosterone patch for the treatment of hypoactive sexual desire disorder in surgically menopausal women: a randomized, placebo-controlled trial. Menopause. 2006; 13(3): 387-96. doi: 10.1097/01.gme.0000179049.08371.c7.

19) Taylor Segraves R, Croft H, Kavoussi R, Ascher JA, Batey SA, Foster VJ, et al. Bupropion sustained release (SR) for the treatment of hypoactive sexual desire disorder (HSDD) in nondepressed women. Journal of Sex \&Marital Therapy. 2001; 27(3): 303-16. doi: 10.1080/009262301750257155.

20) Kashani L, Raisi F, Saroukhani S, Sohrabi H, Modabbernia A, Nasehi AA, et al. Saffron for treatment of fluoxetine - induced sexual dysfunction in women: randomized double - blind placebo - controlled study. Human Psychopharmacology: Clinical and Experimental. 2013; 28(1): 54-60. doi: 10.1002/hup.2282.

21) Belkin ZR, Krapf JM, Goldstein AT. Drugs in early clinical development for the treatment of female sexual dysfunction. Expert opinion on investigational drugs. 2015; 24(2): 159-67. doi: 10.1517/13543784.2015.978283.

22) Khare CP. Indian Herbal Remedies: Rational Western Therapy, Ayurvedic and Other Traditional Usage, Botany: Springer Berlin Heidelberg; 2011.

23) Raghavan S. Handbook of Spices, Seasonings, and Flavorings. Second Edition. CRC Press; 2006.

24) Mohammadi K, Heydari M, Faghihzadeh S. The Female Sexual Function Index-FSFI: Validation of the iranian version. Payesh. 2008; 7(3): 269-78.

25) Gilani, M. Hefz al- Sehe Naseri. Traditional Iranian Medicine. 2011; 2: 157-67.

26) Shafiee-Nick R, Ghorbani A, Vafaee Bagheri F, Rakhshandeh H. Chronic administration of a combination of six herbs inhibits the progression of hyperglycemia and decreases serum lipids and aspartate amino 
transferase activity in diabetic rats. Advances in pharmacological sciences. 2012; 2012. doi: 10.1155/2012/789796.

27) Hosseini A, Mollazadeh H, Amiri MS, Sadeghnia HR, Ghorbani A. Effects of a standardized extract of Rheum turkestanicum Janischew root on diabetic changes in the kidney, liver and heart of streptozotocininduced diabetic rats. Biomedicine \& Pharmacotherapy. 2017; 86: 605-11. doi: 10.1016/j.biopha.2016.12.059. PMID: 28027536.

28) Jala-al-din. Tib-Al-Akbari. Iran, Ghom: Rehabilitation Institute of Natural Medicine; 2008.

29) Orlova A. Sex Diet: A Guidebook to a Healthy Libido: Author House; 2012.

30) Adcock P. Jungle King Secrets: A Libido-Liberating Lifestyle for Superior Sexual Satisfaction. Loving Healing Press; 2008.

31) Mahto D, Singh B, Ahmad M. Effect of feeding concentrate mixture and nutritional supplement in bucks with reduced libido and poor semen quality. Indian Journal of Animal Production and Management. 2009; 25(1/2): 76-7.

32) Eskeland B, Thom E, Svendsen K. Sexual desire in men: effects of oral ingestion of a product derived from fertilized eggs. Journal of international medical research. 1997; 25(2): 62-70. doi: 10.1177/030006059702500202.

33) Guide MS, Chart P-BP, Guide TS, Guide TF, Guide TTH, Guide TJ, et al. Best Natural Ways to Boost Libido in Men.

34) Hurlbert DF, Apt C, Rabehl SM. Key variables to understanding female sexual satisfaction: An examination of women in nondistressed marriages. Journal of sex \& marital therapy. 1993; 19(2): 154-65. doi: 10.1080/00926239308404899. PMID: 8336347.

35) Chambless DL, Sultan FE, Stern TE, O'Neill C, Garrison S, Jackson A. Effect of pubococcygeal exercise on coital orgasm in women. Journal of consulting and clinical psychology. 1984; 52(1): 114. PMID: 6538208 .

36) Sjödin B, Westing YH, Apple FS. Biochemical mechanisms for oxygen free radical formation during exercise. Sports Medicine. 1990; 10(4): 236-54. PMID: 2247725.

37) Alessio HM, Hagerman AE, Fulkerson BK, Ambrose J, Rice RE, Wiley RL. Generation of reactive oxygen species after exhaustive aerobic and isometric exercise. Medicine and science in sports and exercise. 2000; 32(9): 1576-81. PMID: 10994907.

38) Drummond MJ, Fujita S, Takashi A, Dreyer HC, Volpi E, Rasmussen BB. Human muscle gene expression following resistance exercise and blood flow restriction. Medicine and science in sports and exercise. 2008; 40(4): 691. doi: 10.1249/MSS.0b013e318160ff84. PMID: 18317375, PMCID: PMC5088719.

39) Shirazi MA. Kholase al Hekmat. Ghom, Iran: esmailian; 2006: 679.

40) Khare CP. Indian herbal remedies: rational Western therapy, ayurvedic, and other traditional usage, Botany: Springer science \& business media; 2004.

41) Jasicka-Misiak I, Wieczorek PP, Kafarski P. Crotonic acid as a bioactive factor in carrot seeds (Daucus carota L.). Phytochemistry. 2005; 66(12): 1485-91. doi: 10.1016/j.phytochem.2005.04.005. PMID: 15960983.

42) Majumder P, Dasgupta S, Mukhopadhaya R, Mazumdar U, Gupta M. Anti-steroidogenic activity of the petroleum ether extract and fraction 5 (fatty acids) of carrot (Daucus carota L.) seeds in mouse ovary. J Ethnopharmacol. 1997; 57(3): 209-12. PMID: 9292415.

43) Nouri M, Khaki A, Fathi Azad F, Rashidi MR. The protective effects of carrot seed extract on spermatogenesis and cauda epididymal sperm reserves in gentamicin treated rats. Yakhteh Medical Journal. 2009; 11(3): 327-33.

44) Yu LL, Zhou KK, Parry J. Antioxidant properties of cold-pressed black caraway, carrot, cranberry, and hemp seed oils. Food chemistry. 2005; 91(4): 723-9. doi: 10.1016/j.foodchem.2004.06.044.

45) Acton QA. Leukemia: New Insights for the Healthcare Professional: 2013 Edition: ScholarlyEditions; 2013.

46) Rhodes B. Biosynthesis of Alpha-carotene and Beta-carotene in Roots and Tops of Daucus Carota, L: Ann Arbor: UMI; 1983.

47) Murray MT, Pizzorno JE, Pizzorno L. The Encyclopedia of Healing Foods. Atria Books; 2005.

48) Phillips NA. Female sexual dysfunction: evaluation and treatment. American Family Physician. 2000; 62(1): 127-48. PMID: 10905784. 